\title{
Epigenetic dysregulation of secreted frizzled-related proteins in myeloproliferative neoplasms complements the JAK2V617F-mutation
}

Karla Bennemann, Oliver Galm, Stefan Wilop, Claudia Schubert, Tim H Brümmendorf and Edgar Jost*

\begin{abstract}
Background: Secreted frizzled-related proteins (SFRPS) are antagonists of the Wnt signaling pathway, which plays a central role in stem cell maintenance and differentiation of stem cells and hematopoietic progenitors. Epigenetic downregulation of SFRPS by promoter hypermethylation has been described to be involved in the pathogenesis of hematopoietic malignancies. There is an association between aberrant Wnt signaling and the established cancer stem cell concept. In contrast to BCR-ABL1-positive chronic myeloid leukemia CML, BCR-ABL1-negative myeloproliferative neoplasms ( $\mathrm{Ph}^{-} \mathrm{MPN}$ ) are characterized by the frequent occurrence of an autoactivating mutation in the JAK2 tyrosine kinase (JAK2V617F) or other mutations in the JAK-STAT pathway. However, pathogenetic mechanisms of JAK2 mutated or unmutated Ph-MPN remain not completely understood. We determined the promoter methylation status of SFRP-1, -2, -4, and -5 in 57 MPN patient samples by methylation-specific polymerase chain reaction (PCR) (MSP). JAK2V617F was assessed by allele-specific PCR.

Results: Aberrant methylation among primary MPN samples was 4\% for SFRP-1, 25\% for SFRP-2, 2\% for SFRP-4, and $0 \%$ for SFRP-5. Hypermethylation of SFRP-2, which was the most frequently hypermethylated gene in our study, could not be correlated to any specific MPN subtype. However, we detected a significant correlation between SFRP-2 methylation and presence of a JAK2V617F mutation $(P=0.008)$. None of the $10 \mathrm{CML}$ samples showed any SFRP-methylation.

Conclusions: Our data indicate that epigenetic dysregulation of the Wnt signaling pathway is a common event in MPN with aberrant methylation of at least one SFRP being detected in 25\% of the primary patient samples and in $30 \%$ if only accounting for Ph'MPN. A significant correlation between SFRP-2 methylation and presence of JAK2V617F in our data supports the hypothesis that epigenetic dysregulation may be a complementary mechanism to genetic aberrations. Aberrant methylation of crucial stem cell maintenance genes seems to contribute to disease pathogenesis in Ph'MPN.
\end{abstract}

Keywords: DNA hypermethylation, MPN, SFRP, Tumor suppressor gene, JAK2

\footnotetext{
* Correspondence: ejost@ukaachen.de

Clinic for oncology, hematology and stem cell transplantation,

Universitätsklinikum Aachen, RWTH Aachen, Pauwelsstraße 30, Aachen 52074,

Germany
} 


\section{Background}

Classical myeloproliferative neoplasms (MPN) according to the WHO classification constitute a group of hematopoietic malignancies and comprise chronic myeloid leukemia (CML), polycythemia vera (PV), essential thrombocythemia (ET), and primary myelofibrosis (PMF). MPN share a common trait of unregulated trilineage myeloproliferation and monoclonal hematopoiesis originating from genetically transformed hematopoietic stem cells. CML is characterized by the well-known, disease-causing translocation $\mathrm{t}(9 ; 22)$ with the corresponding fusion gene $B C R-A B L 1$. In contrast, $B C R$ $A B L 1$-negative MPN ( $\left.\mathrm{Ph}^{-} \mathrm{MPN}\right)$ present heterogenously in terms of clinical characteristics and cytogenetic aberrations. More than $80 \%$ of chromosomal aberrations are imbalanced changes, with trisomies of chromosomes 8 and 9 being the most frequent aberrations. Further cytogenetic findings are chromosomal deletions of $5 \mathrm{q}, 11 \mathrm{q}$, 13q, 20q, 12p, and Y [1].

The discovery of the Janus kinase 2 (JAK2) V617F mutation in 2005 has modified the understanding of the molecular basis of $\mathrm{Ph}^{-} \mathrm{MPN}$ and resulted in a revision of the WHO diagnostic criteria [2-4]. JAK2 is a receptorassociated protein tyrosine kinase signaling via the JAK/ signal transducer and activator of transcription (JAKSTAT) pathway which plays a key role in a wide spectrum of cellular processes, including proliferation, survival, and normal function of hematopoietic cells. JAK2V617F results from a somatic $\mathrm{G}$ to $\mathrm{T}$ mutation at nucleotide 1849 in exon 14 with consecutive Val617Phe substitution. The mutation affects the non-catalytic pseudo-kinase domain of the JAK2 protein and is responsible for the loss of autoregulatory functionality with constitutive signaling and subsequent hypersensitivity to hematopoietic growth factors. JAK2V617F is by far the most prevalent mutation in $\mathrm{Ph}^{-} \mathrm{MPN}$ with this point mutation being detected in more than $95 \%$ of patients with PV, $50 \%$ of patients with ET, and $50 \%$ of patients with PMF [2,5]. Despite detection of JAK2V617F in other myeloid diseases, JAK2V617F exhibits a broad specificity to patients with myeloid neoplasms. In addition to the JAK2V617F mutation, pathogenesis of the MPN has evolved from a simple to a complex model with a number of novel mutations that have been described in chronic or blast-phase $\mathrm{Ph}^{-} \mathrm{MPN}$. The most prevalent are mutations in JAK2 exon 12, Myeloproliferative Leukemia Virus (MPL), TET oncogene family member (TET2), Additional Sex Combs-like 1 (ASXL1), Casitas B-lineage lymphoma proto-oncogene ( $C B L)$, Isocitrate dehydrogenase (IDH)1 and 2, and IKAROS family zinc finger 1 (IKZF 1) [6]. However, questions remain concerning the initial disease-causing event in $\mathrm{Ph}^{-} \mathrm{MPN}$, the development of phenotypic distinct diseases and the mechanisms leading to transformation in acute myeloid leukemia (AML). There is increasing evidence that epigenetic alterations might contribute to the pathogenetic and phenotypic variety of MPN [7].

Epigenetic alterations have been shown to play an important role in tumorigenesis [8]. In particular, aberrant methylation of $\mathrm{CpG}$ islands within gene promoter regions is associated with transcriptional inactivation and represents an important mechanism of gene silencing in the pathogenesis of hematopoietic malignancies $[9,10]$. Epigenetic disturbances are postulated to be a complementary or alternative mechanism to genetics $[11,12]$. Aberrant CpG island methylation in MPN has been reported for $p 15$ and $p 16$ (cell cycle regulation), as well as for retinoic acid receptor beta 2 (RARß2) and Abelson $(A B L)$ [13,14]. Furthermore, the stromal cellderived factor-1 (SDF-1) receptor CXCR4 is abnormally downregulated in CD34-positive hematopoietic progenitor cells that constitutively circulate in PMF patients. Functional reconstitution with demethylating agents in combination with the histone deacetylase (HDAC) inhibitor results in reduction of in vitro generated JAK2V617F mutated cells [15]. Hypermethylation of the JAK-STAT inhibitor suppressor of cytokine signaling (SOCS) 1 has been shown by independent groups and downregulation of SOCS-3 as well as src homology region 2 domain-containing phosphatase 1 (SHP1) has been found to be associated with promoter methylation in MPN patients [12,16] Further evidence of involvement of epigenetic dysregulation in MPN pathogenesis evolve from the findings of loss-of-function mutations in enhancer of zeste homolog 2 (EZH2), ASXL1 and TET2 with resulting deregulation in both DNA methylation and chromatin structure [17].

To gain additional information about the prevalence and pathogenetic relevance of epigenetic changes as complementary or alternative mechanism in the pathogenesis in MPN, we determined the promoter methylation status of secreted frizzled-related proteins (SFRPS). $S F R P-1,-2,-4$, and -5 possess a CpG island in the promoter region and are antagonists of the Wnt signaling pathway. Consistent with the key functions of the Wnt pathway in stem cell maintenance and differentiation of hematopoietic progenitors, epigenetic downregulation of SFRPs has been described in hematopoietic malignancies $[18,19]$.

\section{Results}

Methylation analysis of SFRP-1, $-2,-4$ and -5

We first analyzed the methylation status of SFRP-1, -2, -4 , and -5 promoter regions by MSP in the human MPN-derived cell lines SET-2 and GDM-1. Methylation was found for SFRP-1, -2, and -5 in GDM-1 cells (Figure 1). None of the four genes showed aberrant methylation in SET-2 cells. Methylation-associated gene 


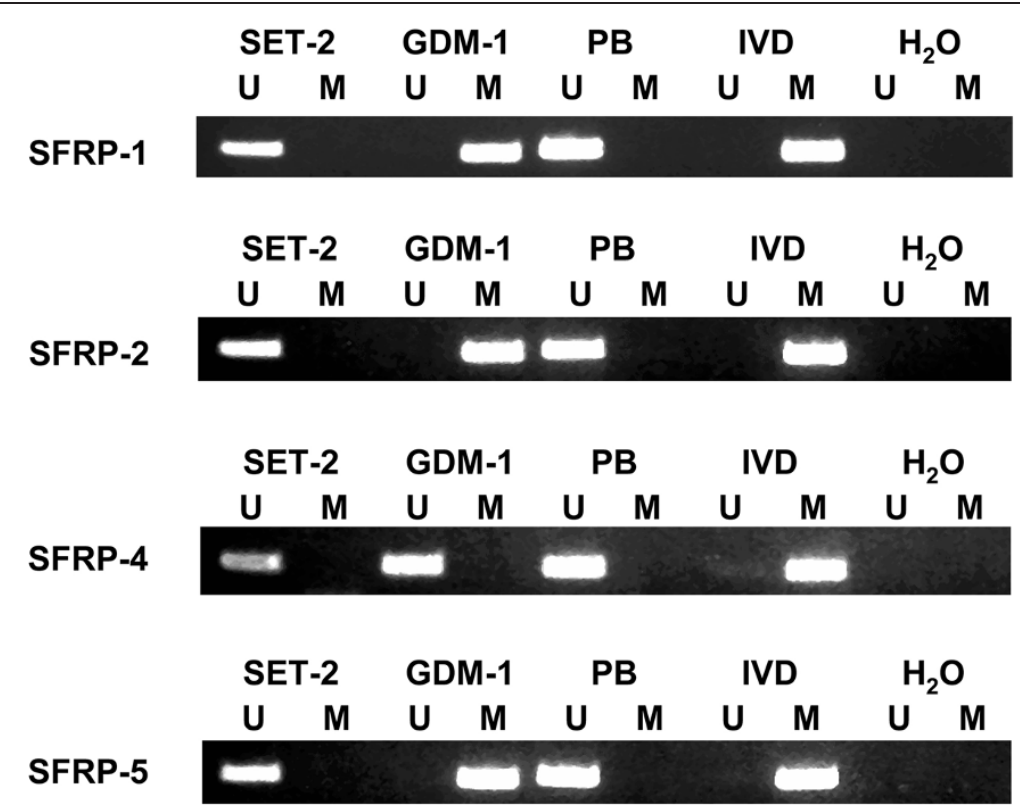

Figure 1 MSP analysis of the four SFRP genes in MPN-derived cell lines and normal peripheral blood (PB). In vitro methylated DNA (IVD) and water served as controls. Lane $U$, amplified product with primers recognizing unmethylated SFRP-1, $-2,-4$, and -5 sequences. Lane $M$, amplified product with primers recognizing methylated SFRP-1, -2, -4 , and -5 sequences.

inactivation of SFRP-1 and -2 in AML cell lines has been published previously [18]. Owing to the functional importance of the Wnt pathway in several hematopoietic malignancies, we then investigated the methylation status of the SFRP promoter regions in $\mathrm{PB}$ and BM from 57 primary MPN patient samples obtained at diagnosis or during follow-up. Table 1 gives an overview of the characteristics of the patient cohort. Representative MSP-results for SFRP-1, -2, -4, and -5 are shown in Figure 2.

The frequency of aberrant methylation among primary MPN patient samples was $4 \%(2 / 57)$ for SFRP-1, $25 \%$ $(14 / 57)$ for SFRP-2, $2 \%(1 / 57)$ for SFRP-4, and 0\% (0/57) for SFRP-5. Aberrant methylation of at least one of the SFRP genes was detected in all $\mathrm{Ph}^{-} \mathrm{MPN}$ subtypes. In contrast, no methylation of any of the SFRPs has been detected in CML samples. Among the $\mathrm{Ph}^{-} \mathrm{MPN}$ subtypes we found methylation of any SFRP in 30\% (3/10) PV- patient samples, 40\% (4/10) ET-patient samples, and 26\% (7/27) MF-patient samples. Regarding the rare methylation of SFRP-4 and -5, only SFRP-1 and -2 were considered for further statistical analyses. We did not see any significant association between SFRP-2 methylation and MPN subtype. However, there was an association of SFRP-1 hypermethylation and diagnosis of ET (2/2 SFRP-1 promoter methylations in ET patients, $P=$ 0.02 ). We could not show any correlation between SFRP-2 methylation and platelet count, peripheral blast cell count, red blood cell count, white blood cell count (WBC), or lactate dehydrogenase in PB. Furthermore, a history of cytostatic therapy did not influence SFRP-2 methylation frequency in our patient cohort.

\section{JAK2 mutation analysis}

Using allele-specific PCR, 47\% (27/57) of the patients showed a signal corresponding to the JAK2 $\mathrm{G}>\mathrm{T}$

Table 1 Characteristics of the patient cohort

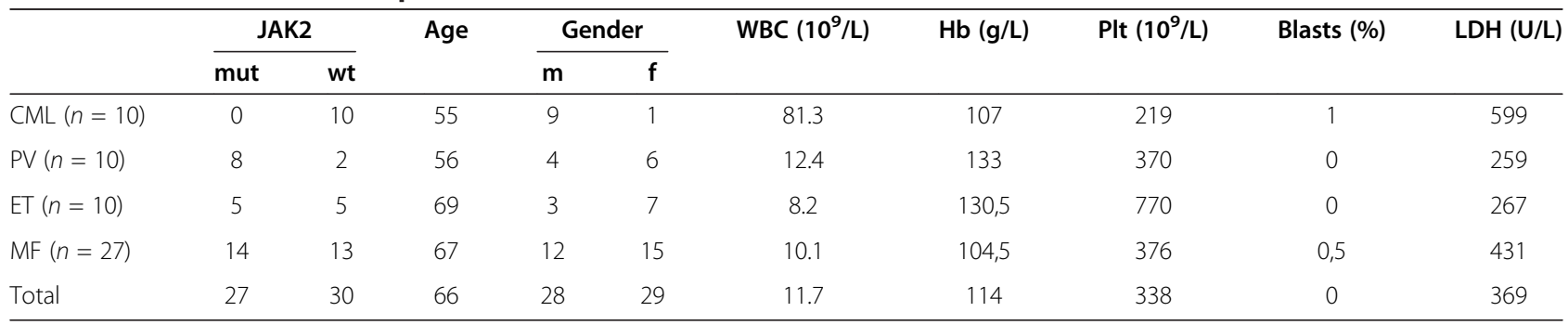

Median values for age, WBC, Hb, Plt, Blasts, LDH. CML, Chronic myeloid leukemia, ET, essential thrombocythemia; $\mathrm{Hb}$, hemoglobin; $\mathrm{LDH}$, lactate dehydrogenase; MF, myelofibrosis; mut, positive for JAK2V617F; plt, platelet count; PV, polycythemiavera; WBC, white blood cell count; wt = negative for JAK2V617F. 


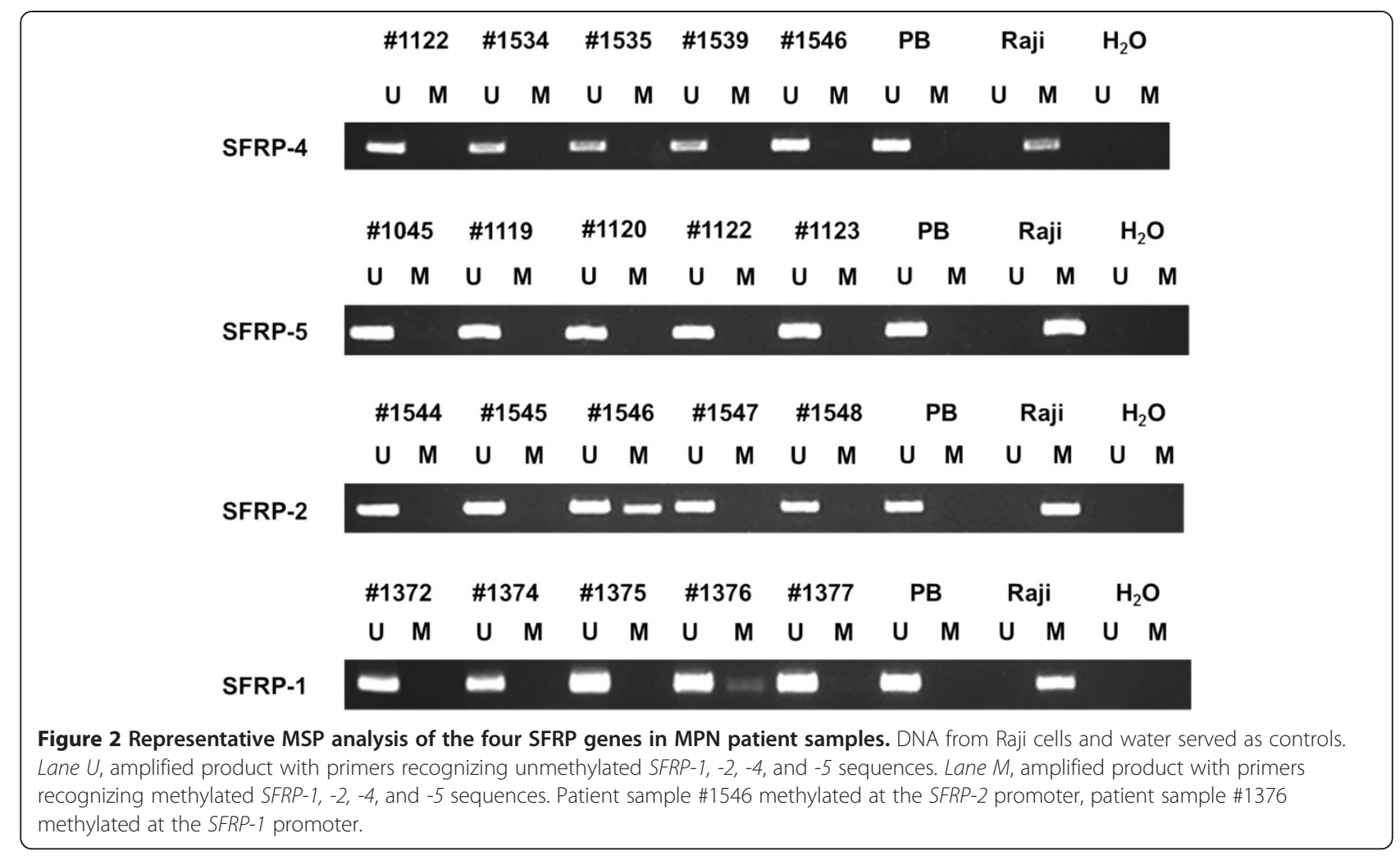

mutation. A total of 50\% (5/10) ET and 80\% (8/10) PV patients had a $J A K 2$ mutation. Among the MF samples, $52 \%(14 / 27)$ carried the mutation. In accordance with expectations we did not detect JAK2V617F in CML patient samples. We could not show any correlation between JAK2V617 mutation and laboratory findings. Importantly, there was no association between previous cytostatic therapy and presence of JAK2V617F. Representative results of the allel-specific PCR are shown in Figure 3.

\section{Epigenetic and genetic changes}

Of the two patient samples methylated at the SFRP-1 promoter, one carried the mutation whereas the other one was wild-type $J A K 2$. In contrast, of the 14 patients with aberrant methylation of SFRP-2, 78.6\% (11/14) were positive for the $J A K 2 V 617 F$ mutation whereas $21.4 \%$ (3/ 14) showed wild-type $J A K 2$. Thus, there is a significant correlation of SFRP-2 methylation occurring in association with a mutated status at JAK2 $(P=0.008)$. Table 2 gives a view of concomitant JAK2 mutation and SFRP-2 promoter methylation in patients with MPN.

\section{Discussion}

To the best of our knowledge, no data have been published so far about aberrant CpG island hypermethylation of SFRP-1, -2, -4, and -5 in the context of $J A K 2$ V617F in $\mathrm{Ph}^{-} \mathrm{MPN}$.

In contrast to CML, a number of novel mutations have been described in BCR-ABL1-negative MPN. Among those are mutations involving JAK2, MPL, TET2, ASXL1, $C B L, I D H$, and IKZF1 $[17,20]$. Wnt signaling plays an 
Table 2 Concomitant JAK2 mutation and SFRP-2 hypermethylation in MPN patients

\begin{tabular}{lllllllll}
\hline & CML $(\boldsymbol{n}=\mathbf{1 0})$ & PV $(\boldsymbol{n}=\mathbf{1 0})$ & ET $(\boldsymbol{n}=\mathbf{1 0})$ & \multicolumn{2}{l}{ MF $(\boldsymbol{n}=\mathbf{2 7})$} \\
\hline SFRP-2 & $\mathrm{U}$ & $\mathrm{M}$ & $\mathrm{U}$ & $\mathrm{M}$ & $\mathrm{U}$ & $\mathrm{M}$ & $\mathrm{U}$ & $\mathrm{M}$ \\
JAK2, wt & 10 & 0 & 1 & 1 & 4 & 1 & 12 & 1 \\
JAK2V617F & 0 & 0 & 6 & 2 & 2 & 3 & 8 & 6
\end{tabular}

$\mathrm{CML}$, chronic myeloid leukemia; $\mathrm{ET}$, essential thrombocythemia; $\mathrm{M}$, methylated; $\mathrm{MF}$, myelofibrosis; PV, polycythemiavera; $\mathrm{U}$, unmethylated; $\mathrm{wt}=$ negative for JAK2V617F.

important role in stem-cell self-renewal as well as in differentiation and proliferation of hematopoietic progenitor cells. Recently, it has been reported that Wnt signaling could be one of the mechanisms that shape a niche in the bone marrow supportive of hematopoiesis [21]. Since aberrant activation of the Wnt pathway has been demonstrated to contribute to leukemogenesis and until now, in contrast to solid tumors, no activating mutations in the genes of the Wnt pathway have been described in myeloid or lymphatic malignancies, we investigated epigenetic regulation of SFRP-1, -2, -4, and -5 as negative regulators of Wnt signaling. Our data indicate that $\mathrm{CpG}$ island hypermethylation of SFRP genes is a frequent event in $\mathrm{Ph}^{-} \mathrm{MPN}$ with aberrant methylation of at least one of the four genes being detected in $30 \%$ of the primary patient samples. Compared to the SFRP methylation patterns in other hematopoietic malignancies, aberrant promoter methylation in our study occurred less frequently than in AML [18]. We could show a preferential hypermethylation of SFRP-1 (4\%) and of SFRP-2 (25\%), in particular. This is in contrast to the methylation frequency of SFRP genes in acute lymphatic leukemia (ALL) [22], where a more balanced methylation frequency of the four genes could be shown, but confirms findings in AML showing a preferential hypermethylation of SFRP-1 (29\%) and SFRP-2 (19\%).

We could show a significant association of SFRP-1 hypermethylation and diagnosis of ET. Regarding the limited number of patient samples methylated at the SFRP-1 promoter (2/57), those results require further confirmation. Furthermore, a study in 52 ET samples did not find any evidence of hypermethylation of soluble Wnt inhibitors [23], whereas our analysis, also using MSP and the same primer sequences, revealed a rate of $40 \%$ of ET samples being methylated.

In contrast to SFRP-1, SFRP-2 hypermethylation in our study occurred in all $\mathrm{Ph}^{-} \mathrm{MPN}$ subtypes without any association with a specific entity. However, there was a significant correlation between aberrant SFRP-2 promoter methylation and the presence of JAK2V617F.

The autoactivating JAK2V617F mutation is responsible for constitutive signaling of the JAK2 protein with subsequent hypersensitivity to hematopoietic growth factors [3]. When comparing the incidence of the JAK2V617F mutation and the frequency among the MPN subtypes with published data, the relative distribution (80\% PV, $50 \% \mathrm{ET}, 52 \% \mathrm{MF}$ ) we obtained in our study is in accordance with previous reports [5]. Limited data are available about epigenetic disturbances in MPN. Increasing evidence suggests that loss-of-function mutations in genes involved in epigenetic regulation, TET2, ASXL1, and $E Z H 2$, as well as JAK2V617F-mediated phosphorylation of protein Arg N-methyltransferase (PRMT5) may play a role in disease pathogenesis, either as 'pre-JAK2 events' or occurring in late phase disease [17,24-26].

Aberrant $\mathrm{CpG}$ island methylation has been reported for $A B L, p 14, p 15, p 16, R A R \beta 2$ [13], and SDF1 receptor CXCR4 [15]. SOCS proteins are the most thoroughly studied inhibitors of JAK-STAT pathways. Silencing of SOCS-1 and -3 in association with promoter hypermethylation has been reported by different groups $[12,16,27]$. However, Capello et al. reported that SOCS-3 methylation was more frequent among JAK2V617Fnegative patients. Nevertheless, the results suggest that epigenetic inactivation seems to play a role in $\mathrm{Ph}^{-} \mathrm{MPN}$. Epigenetics might be a complementary or alternative mechanism to the JAK2V617F mutation in the pathogenesis of $\mathrm{Ph}^{-} \mathrm{MPN}$, leading to dysregulation of JAKSTAT signal transduction and thus to growth factor hypersensitivity. Our findings are in accordance with this hypothesis showing a trend towards an association between JAK2V617F and SFRP-2 hypermethylation, thus, an association between genetic and epigenetic aberrations. Interesting in this context is the comparison of $\mathrm{Ph}^{-} \mathrm{MPN}$ with CML. The identified disease-causing mutation in CML which codes for a fusion-protein with tyrosine kinase activity provides a potential therapeutic target. The clinical success of the tyrosine kinase inhibitor imatinib suggests that the mutation might be one of the main events leading to the pathogenesis of CML. However, regarding the reported Wnt pathway activation in CML cancer stem cells [28] and the reported correlation of SFRP-1 promoter methylation and resistance to imatinib [29] the impact of hypermethylation-associated gene silencing in $\mathrm{CML}$ in contrast to $\mathrm{Ph}^{-} \mathrm{MPN}$ has to be further elucidated. According to our study, SFRP promoter hypermethylation in CML seems to be an uncommon event.

\section{Conclusion}

Despite the discovery of the nearly disease specific $J A K 2$ V617F-mutation and its capacity to induce myeloproliferative disease-like phenotypes in murine models [30], additional genetic or epigenetic events are thought to play an important role in disease initiation. Furthermore, development of three distinct entities from one known mutation has to be explored. Since our patient cohort only consisted of 57 samples and was 
heterogenous for prior treatment regimens, no definitive conclusion can be retained from these data neither regarding the pathogenetic interrelationship of genetic and epigenetic events, nor the phenotypic differences between $\mathrm{Ph}^{-} \mathrm{MPN}$ subtypes or resulting treatment options in a group of diseases with allogenic stem cell transplantation being the only curative concept. Tyrosine kinases are essential therapeutic targets in several diseases and development of inhibitors of JAK2 are being tested in clinical studies. Targeting the epigenome might be a worthwhile effort to complement existing or newly developed therapeutic strategies [6].

\section{Methods}

\section{Human tissue samples}

All samples from patients were collected after informed consent was given. Thirty-four peripheral blood (PB) and 23 bone marrow (BM) specimens were obtained during routine clinical assessment between 1996 and 2007 of 57 adult patients with MPN without any evidence for leukemic transformation. According to standard criteria [31], patients were classified as having CML $(n=10)$, ET $(n=10)$, PV $(n=10)$, and MF $(n=27)$. The collection of patient samples for analysis of genetic and epigenetic changes was approved by the local ethics committee. DNA extraction was performed from unselected cells from BM, when available, or PB. Additionally, we examined the methylation status of MPN-derived cell lines GDM-1 and SET-2.

\section{Methylation analysis of SFRP-1, $-2,-4$, and -5}

$\mathrm{BM}$ and $\mathrm{PB}$ mononuclear cells were isolated by density gradient centrifugation according to standard procedures prior to further analysis. Assessment of peripheral blood mononuclear cells is appropriate regarding the high sensitivity of the applied MSP methods (0.1\%) [32]. For the DNA isolation the QIAmp ${ }^{\circledR}$ DNA Mini Kit (Quiagen, Hilden, Germany) was used according to the manufactures instructions. The methylation status of SFRP-1, -2, -4 , and -5 was investigated by MSP. Approximately $1 \mu \mathrm{g}$ of DNA was chemically modified by sodium bisulfit treatment prior to MSP. This assay converts all unmethylated cytosins to uracil but leaving the methylated cytosins unaffected. Subsequently, amplification with primers specific for methylated $v s$. unmethylated DNA was performed [32]. MSP primer sequences and reaction conditions for SFRP-1, -2, -4 , and -5 have been described previously [33]. The primer specific reaction temperatures were $60^{\circ} \mathrm{C}$ for SFRP-1 and $-2,62^{\circ} \mathrm{C}$ for $S F R P-4$ and $63^{\circ} \mathrm{C}$ for SFRP-5. For every MSP reaction, in vitro methylated DNA (IVD) or the Burkitt lymphoma cell line Raji served as positive and normal PB from healthy volunteers served as negative controls. PCR products were separated on $2.5 \%$ agarose gels and visualized by ethidium bromide staining.

\section{JAK2 mutation analysis}

The mutational status of the JAK2 gene was assessed by allele-specific PCR. Primers and reaction conditions used were previously described [2]. After amplification, the presence of a $J A K 2 V 617 F$ mutation was visualized under UV light on $2 \%$ agarose gels after ethidium bromide staining. In a 1:2 dilution series of DNA from a patient with a homozygous JAK2V617F mutation with normal DNA, the sensitivity of the PCR was shown to be at least $1 / 64$. Direct sequencing of the samples mutated by allele specific PCR confirmed the JAK2V617F mutation in most of the patients and is a proof for a sufficient proportion of clonal cells in the starting material (data not shown). DNA from a patient with a homozygous JAK2V617F mutation was used as a positive control. DNA from a healthy donor was used as a negative control for every PCR reaction.

\section{Statistical methods}

Correlations between variables were analyzed using the Fisher's exact two-sided test and the two-sided Student's $t$-test, respectively. All calculations were performed using the SAS statistical software version 9.1.3.

\section{Competing interests}

The authors declare that they have no competing interests.

\section{Authors' contributions}

KB carried out the molecular genetic analyses, participated in the design of the study, and drafted the manuscript. CS also carried out molecular genetic analyses and made a significant contribution to the general supervision of the research group. EJ, TB, and OG conceived of the study, participated in design and organization of the study, and helped to draft the manuscript. SW performed the statistical analyses. All authors read and approved the manuscript. All authors gave final approval to version to be published.

\section{Acknowledgements}

We thank Lucia Vankann and Peter Glatte for expert technical assistance. This work was supported by a grant from the Deutsche Krebshilfe (author EJ, grant 108475).

Received: 19 June 2012 Accepted: 14 August 2012

Published: 31 August 2012

\section{References}

1. Tefferi A, Dingli D, Li CY, Dewald GW: Prognostic diversity among cytogenetic abnormalities in myelofibrosis with myeloid metaplasia. Cancer 2005, 104:1656-1660.

2. Baxter EJ, Scott LM, Campbell PJ, East C, Fourouclas N, Swanton S, Vassiliou GS, Bench AJ, Boyd EM, Curtin N, Scott MA, Erber WN, Green AR, Cancer Genome Project: Acquired mutation of the tyrosine kinase JAK2 in human myeloproliferative disorders. Lancet 2005, 365:1054-1061.

3. James C, Ugo V, Le Couedic JP, Staerk J, Delhommeau F, Lacout C, Garcon L, Raslova H, Berger R, Bennaceur-Griscelli A, Villeval JL, Constantinescu SN, Casadevall N, Vainchenker W: A unique clonal JAK2 mutation leading to constitutive signalling causes polycythaemia vera. Nature 2005, 434:1144-1148.

4. Tefferi A, Thiele J, Vardiman JW: The 2008 World Health Organization classification system for myeloproliferative neoplasms: order out of chaos. Cancer 2009, 115:3842-3847. 
5. Kralovics R, Passamonti F, Buser AS, Teo SS, Tiedt R, Passweg JR, Tichelli A, Cazzola M, Skoda RC: A gain-of-function mutation of JAK2 in myeloproliferative disorders. N Engl J Med 2005, 352:1779-1790.

6. Mascarenhas J, Roper N, Chaurasia P, Hoffman R: Epigenetic abnormalities in myeloproliferative neoplasms: a target for novel therapeutic strategies. Clin Epigenet 2011, 2:197-212

7. Pardanani A, Fridley BL, Lasho TL, Gilliland DG, Tefferi A: Host genetic variation contributes to phenotypic diversity in myeloproliferative disorders. Blood 2008, 111:2785-2789.

8. Esteller M: Epigenetics in cancer. N Engl J Med 2008, 358:1148-1159.

9. Herman JG, Baylin SB: Gene silencing in cancer in association with promoter hypermethylation. N Engl J Med 2003, 349:2042-2054.

10. Vilas-Zornoza A, Agirre X, Martin-Palanco V, Martin-Subero JI, San Jose-Eneriz E, Garate L, Alvarez S, Miranda E, Rodriguez-Otero P, Rifon J, Torres A, Calasanz MJ, Cruz Cigudosa J, Roman-Gomez J, Prosper F: Frequent and simultaneous epigenetic inactivation of TP53 pathway genes in acute lymphoblastic leukemia. PLOS One 2011, 6:e17012.

11. Hou HA, Kuo YY, Liu CY, Lee MC, Tang JL, Chen CY, Chou WC, Huang CF, Lee FY, Liu MC, Yao M, Tien HF: Distinct association between aberrant methylation of Wnt inhibitors and genetic alterations in acute myeloid leukaemia. Br J Cancer 2011, 105:1927-1933.

12. Jost E, do ON, Dahl E, Maintz CE, Jousten P, Habets L, Wilop S, Herman JG, Osieka R, Galm O: Epigenetic alterations complement mutation of JAK2 tyrosine kinase in patients with BCR/ABL-negative myeloproliferative disorders. Leukemia 2007, 21:505-510.

13. Kumagai $T$, Tefferi A, Jones $L$, Koeffler HP: Methylation analysis of the cell cycle control genes in myelofibrosis with myeloid metaplasia. Leuk Res 2005, 29:511-515.

14. Wang JC, Chen W, Nallusamy S, Chen C, Novetsky AD: Hypermethylation of the P15INK4b and P16INK4a in agnogenic myeloid metaplasia (AMM) and AMM in leukaemic transformation. Br J Haematol 2002, 116:582-586

15. Shi J, Zhao Y, Ishii T, Hu W, Sozer S, Zhang W, Bruno E, Lindgren V, Xu M, Hoffman R: Effects of chromatin-modifying agents on CD34+ cells from patients with idiopathic myelofibrosis. Cancer Res 2007, 67:6417-6424.

16. Capello D, Deambrogi C, Rossi D, Lischetti T, Piranda D, Cerri M, Spina V, Rasi S, Gaidano G, Lunghi M: Epigenetic inactivation of suppressors of cytokine signalling in Philadelphia-negative chronic myeloproliferative disorders. Br J Haematol 2008, 141:504-511.

17. Vainchenker W, Delhommeau F, Constantinescu SN, Bernard OA: New mutations and pathogenesis of myeloproliferative neoplasms. Blood 2011, 118:1723-1735.

18. Jost E, Schmid J, Wilop S, Schubert C, Suzuki H, Herman JG, Osieka R, Galm $\mathrm{O}$ : Epigenetic inactivation of secreted Frizzled-related proteins in acute myeloid leukaemia. Br J Haematol 2008, 142:745-753.

19. Liu TH, Raval A, Chen SS, Matkovic JJ, Byrd JC, Plass C: CpG island methylation and expression of the secreted frizzled-related protein gene family in chronic lymphocytic leukemia. Cancer Res 2006, 66:653-658

20. Tefferi A: Novel mutations and their functional and clinical relevance in myeloproliferative neoplasms: JAK2, MPL, TET2, ASXL1, CBL, IDH and IKZF1. Leukemia 2010, 24:1128-1138.

21. Ichii M, Frank MB, lozzo RV, Kincade PW: The canonical Wnt pathway shapes niches supportive of hematopoietic stem/progenitor cells. Blood 2012, 119:1683-1692.

22. Roman-Gomez J, Cordeu L, Agirre X, Jimenez-Velasco A, San Jose-Eneriz E, Garate L, Calasanz MJ, Heiniger A, Torres A, Prosper F: Epigenetic regulation of Wnt-signaling pathway in acute lymphoblastic leukemia. Blood 2007, 109:3462-3469.

23. Chim CS, Fung TK, Liang R: Methylation of cyclin-dependent kinase inhibitors, XAF1, JUNB, CDH13 and soluble Wnt inhibitors in essential thrombocythaemia. J Clin Pathol 2010, 63:518-521.

24. Liu F, Zhao X, Perna F, Wang L, Koppikar P, Abdel-Wahab O, Harr MW Levine RL, Xu H, Tefferi A, Deblasio A, Hatlen M, Menendez S, Nimer SD: JAK2V617F-mediated phosphorylation of PRMT5 downregulates its methyltransferase activity and promotes myeloproliferation. Cancer Cell 2011, 19:283-294.

25. Score J, Hidalgo-Curtis C, Jones AV, Winkelmann N, Skinner A, Ward D, Zoi K, Ernst T, Stegelmann F, Dohner K, Chase A, Cross NC: Inactivation of polycomb repressive complex 2 components in myeloproliferative and myelodysplastic/myeloproliferative neoplasms. Blood 2012,

119:1208-1213.
26. Tefferi A, Pardanani A, Lim KH, Abdel-Wahab O, Lasho TL, Patel J, Gangat N, Finke CM, Schwager S, Mullally A, Li CY, Hanson CA, Mesa R, Bernard O, Delhommeau F, Vainchenker W, Gilliand DG, Levine RL: TET2 mutations and their clinical correlates in polycythemia vera, essential thrombocythemia and myelofibrosis. Leukemia 2009, 23:905-911.

27. Teofili L, Martini M, Cenci T, Guidi F, Torti L, Giona F, Foa R, Leone G, Larocca LM: Epigenetic alteration of SOCS family members is a possible pathogenetic mechanism in JAK2 wild type myeloproliferative diseases. Int J Cancer 2008, 123:1586-1592.

28. Jamieson CH, Ailles LE, Dylla SJ, Muijtjens M, Jones C, Zehnder JL, Gotlib J, Li K, Manz MG, Keating A, Sawyers CL, Weissman IL: Granulocytemacrophage progenitors as candidate leukemic stem cells in blast-crisis CML. N Engl J Med 2004, 351:657-667.

29. Pehlivan M, Sercan Z, Sercan HO: sFRP1 promoter methylation is associated with persistent Philadelphia chromosome in chronic myeloid leukemia. Leuk Res 2009, 33:1062-1067.

30. Wernig G, Mercher T, Okabe R, Levine RL, Lee BH, Gilliland DG: Expression of Jak2V617F causes a polycythemia vera-like disease with associated myelofibrosis in a murine bone marrow transplant model. Blood 2006, 107:4274-4281.

31. Vardiman JW, Harris NL, Brunning RD: The World Health Organization (WHO) classification of the myeloid neoplasms. Blood 2002, 100:2292-2302.

32. Herman JG, Graff JR, Myohanen S, Nelkin BD, Baylin SB: Methylationspecific PCR: a novel PCR assay for methylation status of CPG islands. Proc Natl Acad Sci U S A 1996, 93:9821-9826.

33. Suzuki H, Watkins DN, Jair KW, Schuebel KE, Markowitz SD, Dong Chen W, Pretlow TP, Yang B, Akiyama Y, Van Engeland M, Toyota M, Tokino T, Hinoda Y, Imai K, Herman JG, Baylin SB: Epigenetic inactivation of SFRP genes allows constitutive WNT signaling in colorectal cancer. Nat Genet 2004, 36:417-422.

doi:10.1186/1868-7083-4-12

Cite this article as: Bennemann et al:: Epigenetic dysregulation of secreted frizzled-related proteins in myeloproliferative neoplasms complements the JAK2V617F-mutation. Clinical Epigenetics 2012 4:12.

\section{Submit your next manuscript to BioMed Central and take full advantage of:}

- Convenient online submission

- Thorough peer review

- No space constraints or color figure charges

- Immediate publication on acceptance

- Inclusion in PubMed, CAS, Scopus and Google Scholar

- Research which is freely available for redistribution
C BioMed Central 